\title{
New bedrock map of Dome C, Antarctica, and morphostructural interpretation of the area
}

\author{
Alessandro FORIERI, ${ }^{1,4}$ Luisa ZUCCOLI, ${ }^{2}$ Alfredo BINI, ${ }^{2}$ Achille ZIRIZZOTTI, ${ }^{3}$

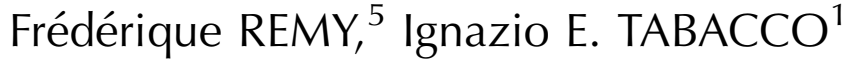 \\ ${ }^{1}$ Università degli Studi di Milano, Sez. Geofisica, Via Cicognara 7, I-20129 Milan, Italy \\ E-mail: alessandro.forieri@unimi.it \\ ${ }^{2}$ Università degli Studi di Milano, Sez. Geologia, Via Mangiagalli 34, I-20133 Milan, Italy \\ ${ }^{3}$ Istituto Nazionale Geofisica e Vulcanologia, Via di Vigna Murata 605, I-00143 Rome, Italy \\ ${ }^{4}$ Università degli Studi di Siena, Dip. Scienze della Terra, Via del Laterino 8, I-53100 Siena, Italy \\ ${ }^{5}$ Laboratoire d'Etudes en Géophysique et Océanographie Spatiales, 18 av. Edouard Belin, 31055 Toulouse Cedex, France
}

\begin{abstract}
A new bedrock map of the Dome $C$ area is presented, based on all radar data collected during Italian Antarctic Expeditions in 1995, 1997, 1999 and 2001. The map clearly distinguishes the Dome $\mathrm{C}$ plateau, along with valleys and ridges. The plateau develops at three different altimetric levels, and its morphology is characterized by hills and closed depressions. There are no visible features which can be ascribed to glacial erosion or deposition. The major valley is $15 \mathrm{~km}$ wide and $500 \mathrm{~m}$ deep; its axis is parallel to that of other valleys and ridges in the plateau. The valley bottom is not flat, but contains a saddle at its centre. The morphology of the major valley may be considered a relict one which was not modified by the overlying ice cap. Two large ridges, characterized by hills, saddles and depressions, lie near the boundaries of the area. The map is used to recalculate ice thickness below the European Project for Ice Coring in Antarctica (EPICA) borehole. The new thickness is $3300 \mathrm{~m}, 50 \mathrm{~m}$ greater than before, implying that the expected palaeoclimate record from the ice core could extend back $>800 \mathrm{kyr}$.
\end{abstract}

\section{INTRODUCTION}

A large number of airborne and ground-based radar data were collected in the Dome $C$ area during Italian Antarctic Expeditions in 1995, 1997, 1999 and 2001. Based only on radar data of 1995, a map of the Dome C area was produced by Tabacco and others (1998). The aim of this work is to analyze the new data, compare the ice-thickness value at cross-points and create a new map with all data, in order to obtain a better definition of the main morphological characteristics already evidenced.

\section{RADAR SYSTEMS AND DATA COLLECTION}

We used different radar systems from 1995 to 2001 (Tabacco and others, 1998, 1999), with technical data being reported in Table 1 . The study area covers a $120 \mathrm{~km} \times 80 \mathrm{~km}$ rectangle centred at Dome C. Figure 1 shows the paths along which radar data were collected. The total length of radar lines in the area is about $3700 \mathrm{~km}$ $(3500 \mathrm{~km}$ of airborne surveys and $200 \mathrm{~km}$ of ground surveys). The cruising speed during the airborne survey (on board a Twin Otter aircraft) was $185-220 \mathrm{~km} \mathrm{~h}^{-1}$, and the average elevation above the glacier, controlled by radar altimeter, was $350 \mathrm{~m}$ or, in some cases, $700 \mathrm{~m}$. The travelling speed of the ground-based survey (on board a Pisten Bully tractor) was $7.5-18.5 \mathrm{~km} \mathrm{~h}^{-1}$. The positioning of the radar paths was obtained by navigation solutions based on a single rover global positioning system (GPS) receiver Trimble 4000 SSE which provided time synchronization with the radar system. The GPS data-acquisition frequency was $5 \mathrm{~s}$ for airborne radar surveys and $15 \mathrm{~s}$ for ground-based surveys. Raw data consist of about 150000 traces; however, traces are not homogeneous due to differences in radar systems and track-acquisition rates. All data were processed using the same criteria, and a dataset of bedrock elevation was created for the area.

\section{BEDROCK ELEVATION CALCULATION AND ERROR ANALYSIS}

Bedrock elevation was calculated by subtracting ice thickness from surface altimetry. Surface altimetry data were obtained from European Remote-sensing Satellite-1 (ERS-1) satellite imagery on a regular grid of $1 / 30^{\circ}$ (Rémy and others, 1999).

Ice thickness was calculated from the two-way reflection time assuming a constant electromagnetic-wave propagation velocity in ice of $168 \mathrm{~m} \mathrm{ss}^{-1}$ (Glen and Paren, 1975; Bogorodsky and others, 1985). The wave speed is accurate to $\pm 0.5 \mathrm{~m} \mathrm{\mu s}^{-1}$ (Glen and Paren, 1975) and corresponds to an error of $9 \mathrm{~m}$ in $3000 \mathrm{~m}$ of ice.

In ice-thickness calculation, errors mainly arise from changes in aircraft elevation and from the selected time for sampling reflections from the surface and base of the ice

Table 1. Main characteristics of the radar systems used by Programma Nazionale di Ricerche in Antartide (PNRA)

\begin{tabular}{lcccc}
\hline & 1995 & 1997 & 1999 & 2001 \\
\hline Operating frequency $(\mathrm{MHz})$ & 60 & 60 & 60 & 60 \\
Peak power $(\mathrm{kW})$ & 1 & 1 & 1 & 1 \\
Trace length (samples) & 512 & 1024 & 1280 & 1280 \\
Sampling rate $(\mathrm{ns})$ & 100 & 50 & 50 & 50 \\
Total sampling time $(\mu \mathrm{s})$ & 51.2 & 51.2 & 64 & 64 \\
Pulse length $(\mu \mathrm{s})$ & 1 & 1 & 1 & 0.5 \\
Acquired traces s $^{-1}$ & 0.33 & 1 & 10 & 10 \\
\hline
\end{tabular}




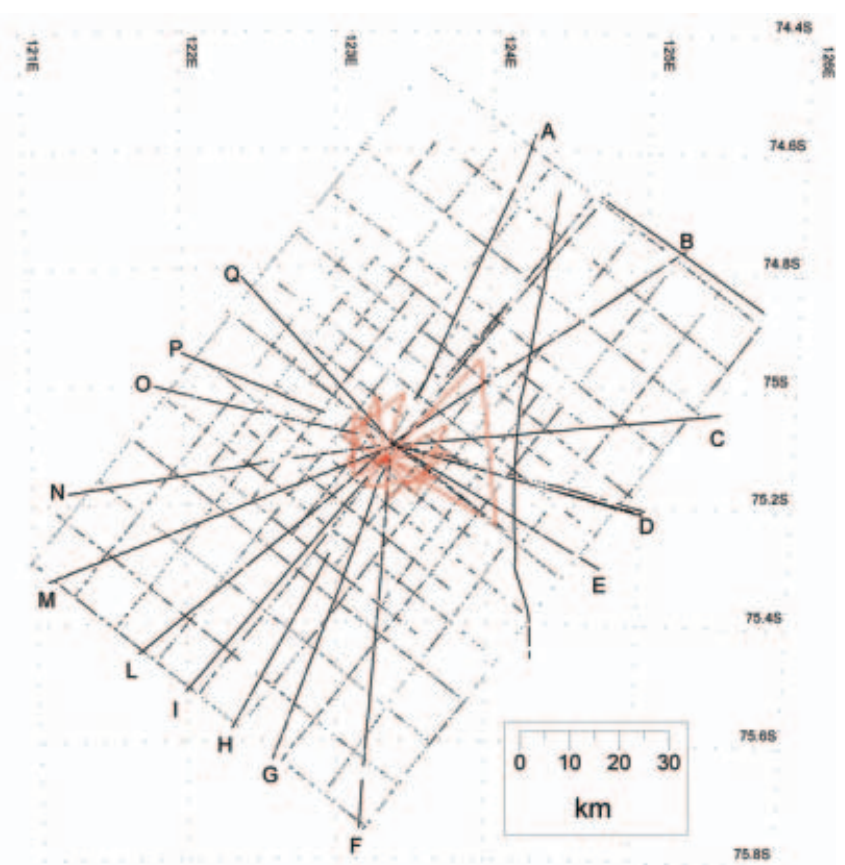

Fig. 1. Position of radar data collected by PNRA. Red points indicate ground-based survey, black points airborne survey. Grid spacing is $10 \mathrm{~km}$, increasing to $5 \mathrm{~km}$ near Dome C. Dome C is at the centre of the grid. sheet. The error in selecting the surface and bed surfaces is \pm 1 sample; considering the difference in the accuracy of radar systems, this corresponds to errors in surface measurements of about $\pm 15 \mathrm{~m}$ for data collected in 1995 and of $\pm 7.5 \mathrm{~m}$ for other data, and to errors in bedrock values of about $\pm 8.4 \mathrm{~m}$ for data collected in 1995 and of $\pm 4.2 \mathrm{~m}$ for other data. No correction accounting for lower-density firn was applied, giving rise to a systematic error; considering a $100 \mathrm{~m}$ thick firn layer in the Dome C area, all glacier thickness values were underestimated by approximately $10 \mathrm{~m}$ (Rasmussen, 1986; Paterson, 1994). No correction for migration was applied.

Finally, errors in the horizontal positioning of the aircraft using global positioning system (GPS) navigation solutions are estimated to be $\pm 20 \mathrm{~m}$. Considering the surface slope and the ice-thickness change, the induced error in surface elevation is completely negligible $(4 \mathrm{~cm})$, while it is $1 \mathrm{~m}$ in bedrock elevation (Retzlaff and others, 1993). The rootmean-square sum of all errors yields a total ice-thickness error of about $22 \mathrm{~m}$ for data collected in 1995 and of $16 \mathrm{~m}$ for other data.

\section{BED TOPOGRAPHY MAP}

The previous map (Tabacco and others, 1998) was based on 2470 data points from the 1995 radar survey alone. New radar surveys and processing techniques allowed us

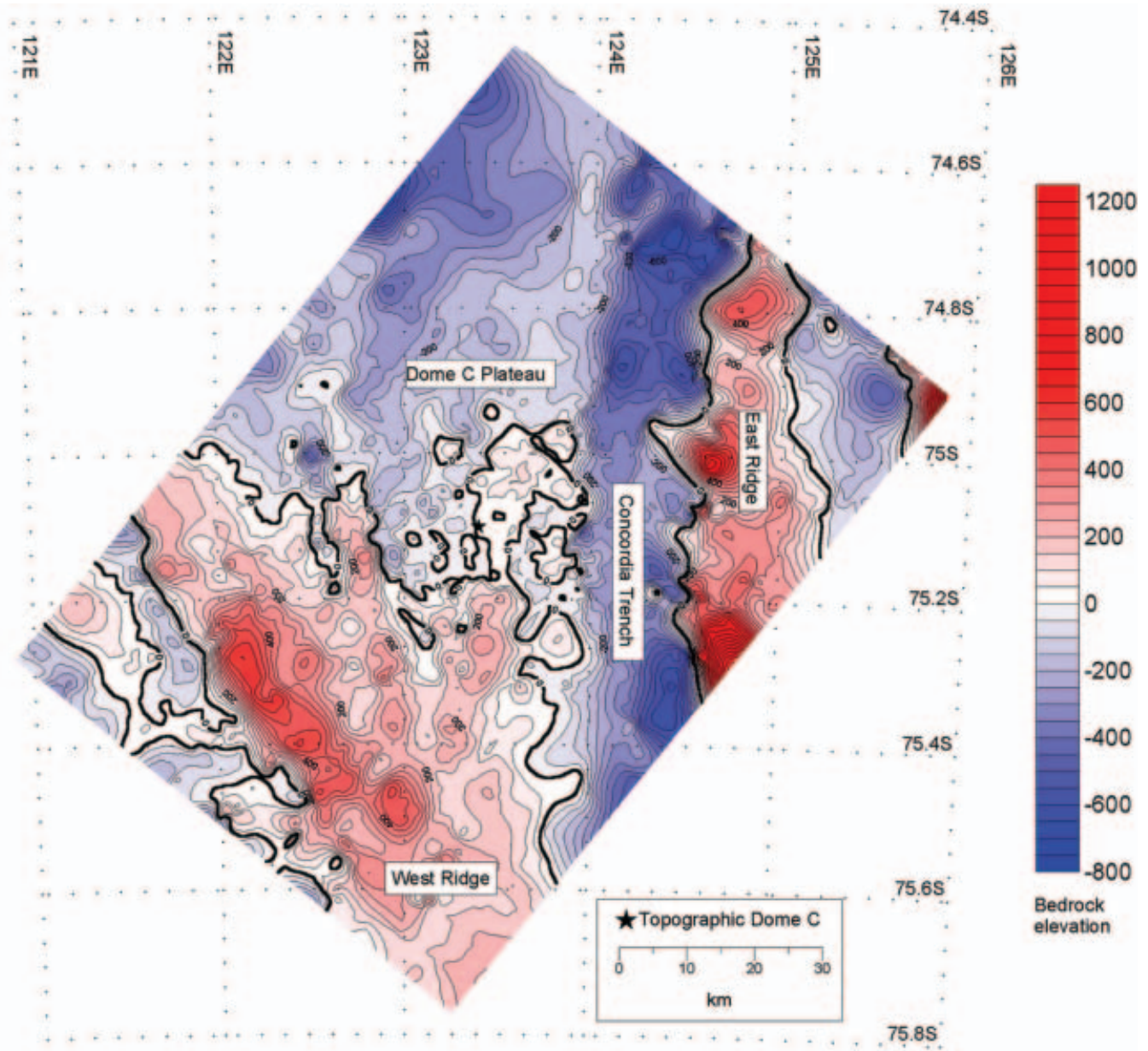

Fig. 2. Two-dimensional bedrock topography of Dome C area. Contour lines every $50 \mathrm{~m}$. Elevations are expressed as height above World Geodetic System 1984 (WGS84) ellipsoid. 
to obtain $>51000$ ice-thickness data (about one-third of the acquired raw data). Before interpolation and contour analysis, we determined ice-thickness values at all points where radar legs intersect. An intersection is defined by two points belonging to two different legs. We consider as intersections neighbouring points closer than $1000 \mathrm{~m}$. We identified $>700$ intersections in the whole area: $50 \%$ are $<200 \mathrm{~m}$ apart and $70 \%$ differ in ice thickness by $<40 \mathrm{~m}$.

Three different gridding methods (kriging, inverse of distance and minimum curvature) were compared to interpolate and contour the data: best results were produced by the minimum curvature method on a regular grid of $100 \times 71$ points, corresponding to a spacing between gridlines of about $1.3 \mathrm{~km}$. Points between legs are subject to interpolation errors, and this error is greater where the interpolation surface is rougher. The map of residuals, i.e. the map of the differences between observed and interpolated values, shows that the largest differences are mainly east and south of Dome C, in mountainous areas where bedrock gradients are high. The interpolation error is estimated to be $15 \mathrm{~m}$.

Figure 2 shows the new bedrock map. We verified that the chosen interpolation method did not produce any significant distortion of the main features observed in the radio-echo sounding profiles and that, especially on the Dome C plateau, hills and bumps and smooth undulations are not a numerical artefact. To do so, we compared the original radar profile with the same profile obtained from the map (Fig. 3).

\section{EPICA DRILLING-SITE ICE THICKNESS}

All radar data have been acquired on a network centred on topographic Dome C (75 $\left.06^{\prime} 06.35^{\prime \prime} \mathrm{S}, 123^{\circ} 23^{\prime} 42.76^{\prime \prime} \mathrm{E}\right)$, where the ice thickness was calculated as $3250 \pm 25 \mathrm{~m}$ by Tabacco and others (1998). The actual drilling site of Concordia station base camp is located about $1400 \mathrm{~m}$ east of the topographic dome, at $75^{\circ} 06^{\prime} 03.74^{\prime \prime} \mathrm{S}$, $123^{\circ} 20^{\prime} 52.10^{\prime \prime} \mathrm{E}$ (personal communication from L. Vittuari, 2002). Below this point we recalculate the ice thickness, creating a square map $(15 \mathrm{~km} \times 15 \mathrm{~km})$ with gridlines spaced $400 \mathrm{~m}$ apart. Near the location of the base camp indicated by Vittuari, there is a radar leg collected in 1995. The nearest point of this leg is $35 \mathrm{~m}$ from the base camp, and the measured ice thickness at this location is $3309 \pm 22 \mathrm{~m}$. According to our interpolated map, the ice thickness below the EPICA drilling site is $3299 \mathrm{~m}$. These values are about $50 \mathrm{~m}$ greater than the previous estimate; if the new estimates are correct and drilling does reach the bedrock, the ice core could provide a palaeoclimate record older than 800 kyr BP.

\section{DESCRIPTION AND MORPHOLOGICAL INTERPRETATION OF THE AREA}

When interpreting radar profiles of the Dome $C$ area, one must bear in mind that data at the centre of the area (around Dome C) are denser and more significant than in the external zones. At the centre, geomorphological features are smaller and show greater detail, becoming fewer and larger away from the centre (Fig. 4).

The radar profiles acquired in 1999 and 2001 highlight some very small, extremely detailed structures; however, these are smoothed by the interpolation method, so only
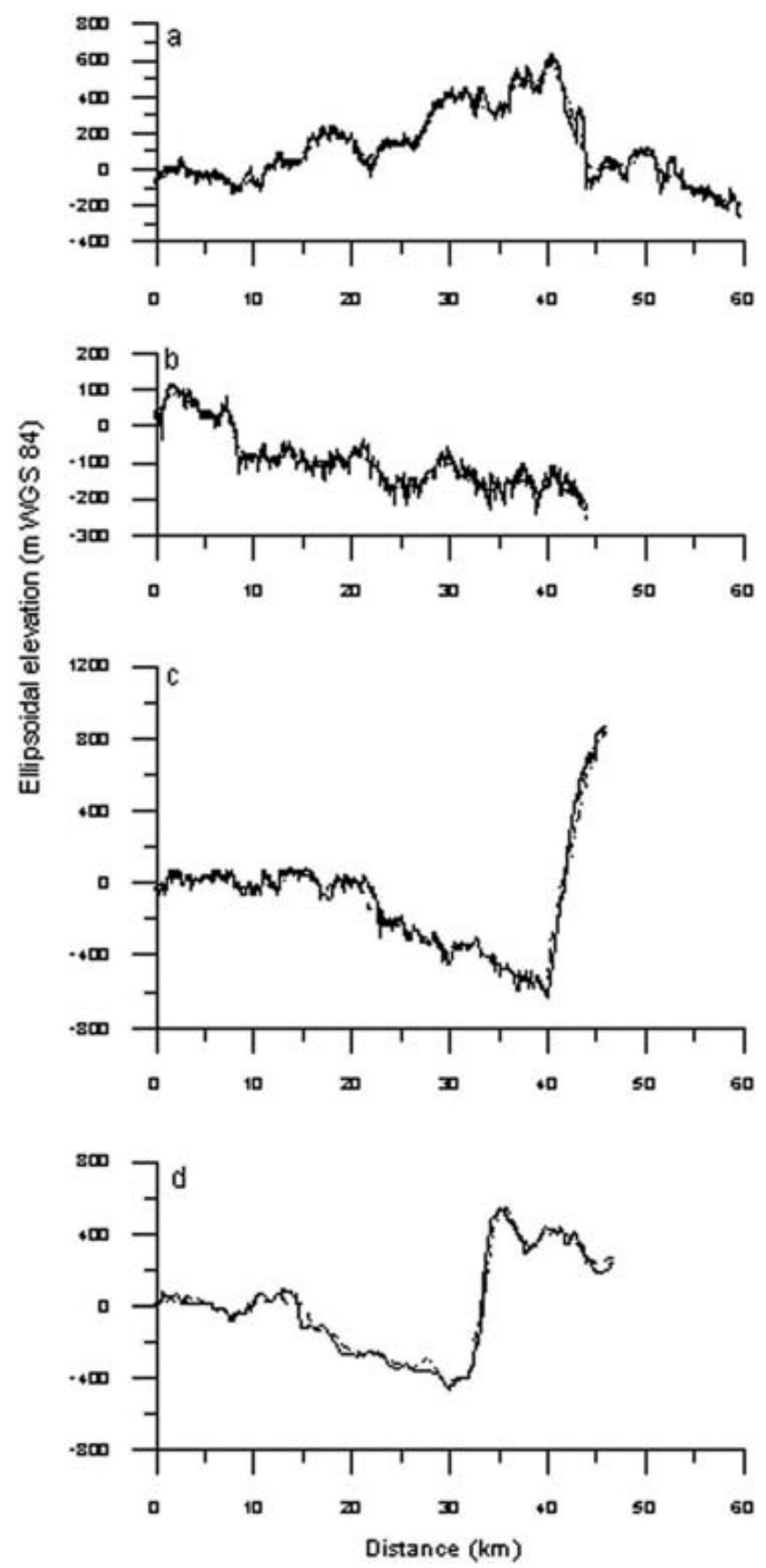

Fig. 3. Comparison between original radar data (solid line) and interpolated data (dashed line) for some relevant profiles: (a) profile L; (b) profile A with enlarged vertical scale; (c) profile E; (d) profile D.

major structures are revealed in the map. Despite such data processing, the observed topography is a true representation of reality, because the error is smaller than the contour interval. Figure 3 shows a comparison between original radar profiles and interpolated data.

On a small scale, the central portion of the area reveals an irregular plateau which dips to the northwest; it is bordered to the east by a valley (Concordia Trench) and a parallel ridge (East Ridge), and to the southwest and west by another ridge (West Ridge). Beyond these two ridges, to the east and southwest, there are two other valleys, but the low density of the data does not allow them to be interpreted correctly. 


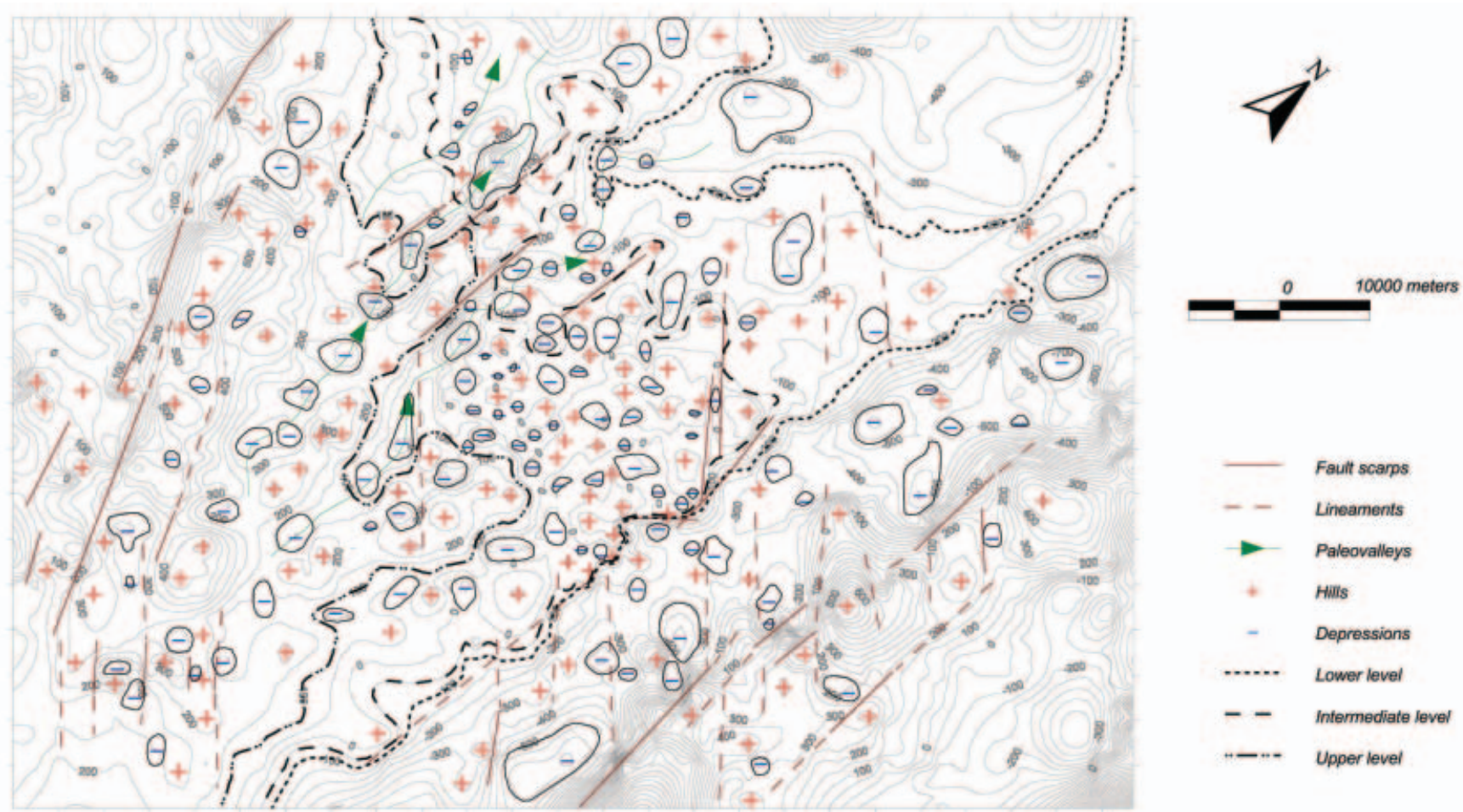

Fig. 4. Subglacial geomorphology of Dome C area.

On a larger scale, the plateau develops on three levels:

the lower level lies roughly between -100 and $-200 \mathrm{~m}$ above the World Geodetic System 1984 (WGS84) ellipsoid (h.a.e.) contour lines and dips north-northwest in a depressed morphology which cannot be better defined due to the sparseness of data. This level extends to the north, forming a wide divide between the latter depression and the Concordia Trench. It is not present to the south, along the flank of the Concordia Trench.

the intermediate level lies between the -50 and +100 ( $m$ h.a.e.) contour lines and corresponds to the position of Dome C.

the upper level is delimited below by the +150 ( $\mathrm{m}$ h.a.e.) contour line and joins with the West Ridge.

Two minor ridges, which radiate southward from the beginning of the West Ridge, run across the three levels. One of the minor ridges is roughly parallel to the Concordia Trench, while the other runs slightly to the west. Two small valleys lie between the two minor ridges and between these and the West Ridge. Although the transition between levels may seem gradual, most of the radar profiles highlight escarpments (profiles A, M, I, O in Fig. 1), interpreted as fault scarps. Even when no migration analysis was done, this feature was controlled and confirmed through the comparison between intersecting profiles.

The surface of all levels of the plateau is characterized by the presence of a series of hills and mostly closed depressions. As mentioned earlier, the smaller size of both hills and depressions at the centre of the area is due to the higher density of data points.

Radar profiles (e.g. G, M, I, L) show a continuous succession of hills and depressions of extremely variable size: large domes with surfaces marked by minor hills and depressions; towers delimited by probable fault scarps, with upper surfaces marked by minor hills and depressions; small hills and depressions on an undulate surface.

Hills and depressions of different size are also present in the minor valleys delimited by ridges. The flanks of these structures are either scarps, considered fault scarps (e.g. O, P, Q) or the slopes of major hills (e.g. L).

The West Ridge (e.g. L, I, M), which generally connects regularly with the upper level of the plateau, shows a similar surface morphology, although the towers delimited by scarps are more numerous and apparent. To the west, the ridge is delimited by a series of high fault scarps which separate it distinctly from the plateau and the western depressions.

The Concordia Trench is a very large valley, about $15 \mathrm{~km}$ wide and at most $500 \mathrm{~m}$ deep, with a characteristic morphology. The eastern slope of the valley, by the East Ridge, is very steep, and marked by probable fault scarps (profiles D, E, C, B). The western slope, by the plateau, is sometimes regular (profile $\mathrm{E}$ ), but generally marked by smaller, less inclined fault scarps with respect to those of the other slope (profiles D, C, B). The transverse profile of the valley varies from flat (e.g. C, B) to east-dipping (e.g. D, E). There are large depressions and rare major hills along the valley floor; the detailed relief shows a low density of hills and depressions. Due to the presence of a central wide saddle (profile D), the valley does not have a linear longitudinal profile but dips both to the north and south starting from the saddle. The East Ridge is characterized by very marked hills delimited by fault scarps (profile C) and separated by wide saddles (profile B). Aligned structures and parallel lineaments are present at all scales of observation; their trends intersect at varying angles. Many lineaments were identified on radar profiles and interpreted as fault scarps. 
The structural control on the morphology of the area is quite apparent. As suggested by $\mathrm{P}$. Cianfarra and others (personal communication, 2003), the morphology reflects a generalized extensional regime, with movement mainly occurring along faults that delimit the ridges. In particular, on the slope of the Concordia Trench, a fault set dipping $60^{\circ} \mathrm{W}$ with a vertical displacement of $1100-1300 \mathrm{~m}$ (personal communication from P. Cianfarra and others, 2003) tilts the entire structure of the plateau and produces the uplifting of the East Ridge. The extensional regime in the area produces a general horst-and-graben structure, whereby many hills are actually horsts and many basins are grabens. The Concordia Trench itself is a structural basin consisting of a set of grabens. Although many of the larger hills and basins are structural elements, the minor ones seen on radar profiles require a different explanation.

\section{HYPOTHESIS FOR THE ORIGIN OF THE DESCRIBED MORPHOLOGY}

Over the whole area, the landscape can be described as a hill-and-depression landscape, with no traces of glacial, erosional or depositional elements. The Concordia Trench is certainly a structural depression and not a glacial valley. Indeed, it would be impossible to have glacial erosion at Dome $\mathrm{C}$ since the ice is presently stagnant or flows extremely slowly (Rémy and Tabacco, 2000). The detailed radar profiles clearly show that the hills or ridges cannot be drumlins (Rémy and Tabacco, 2000), and the geometry of the hills, reconstructed using the minimum curvature interpolation method, is not that of a drumlin field.

There are no elements which would indicate a fluvial or subglacial morphology or a subaerial morphology: the Concordia Trench is not a river valley, as shown by its longitudinal profile.

Due to the presence of faults and elements of extensional tectonics, the described morphology cannot be ascribed to isostasy, which involves slow subsidence with no brittle deformation and is incompatible with extensional structures. Consequently, the observed landscape cannot have formed beneath the Antarctic ice cap and could therefore pre-date its formation.

Considering that the morphology of the Dome $\mathrm{C}$ area is mainly determined by tectonic processes, the detailed morphology of hills and valleys may be the result of two different processes:

weathering of granitic rocks, with the development of a 'demi-oranges' and inselberg landscape;

karstification of limestones, and development of a cone karst.

As we cannot determine the lithology of the substrate, we cannot definitely exclude either hypothesis.

Dome C is in a craton (Dalziel, 1999), so the substrate is probably granitic; however, there may also be a limestone substrate linked to Cretaceous transgression. Limestones of this age are present in Australia (Twidale, 1997) and pre-date the break-up of Antarctica and Australia; we must therefore consider the possible presence of limestones below the ice cap. The landforms are more typical of a karst environment. The depressions in the valleys are also more easily explained by the presence of limestones than by a granitic substrate; indeed the landscape is similar to a drainage network disrupted by karst.

\section{CONCLUSIONS}

The landscape below the Dome C area, reconstructed through radar profiles, could not have developed below the ice cap and cannot be ascribed to glacial activity or isostatic subsidence. It is concluded that the bedrock morphology developed before the ice cap and was not significantly modified by subsequent glacial activity. Two hypotheses are proposed to explain the origin of the subglacial morphology: weathering of granitic rocks, and limestone karstification. Both proposed genetic hypotheses call for a warm, humid climate and a long period of stability in a continental environment. Furthermore, the distribution of hills and valleys indicates that they formed after tectonic deformation in the area.

\section{ACKNOWLEDGEMENTS}

Research was carried out within the framework of the Glaciology Project of the Programma Nazionale di Ricerche in Antartide (PNRA) and was financially supported by the Ente per le Nuove tecnologie, l'Energia e l'Ambiente (ENEA). This work is a contribution to the 'European Project for Ice Coring in Antarctica' (EPICA), a joint European Science Foundation (ESF)/European Commission (EC) scientific programme, funded by the $\mathrm{EC}$ and by national contributions from Belgium, Denmark, France, Germany, Italy, the Netherlands, Norway, Sweden, Switzerland and the United Kingdom.

\section{REFERENCES}

Bogorodsky, V. V., C.R. Bentley and P.E. Gudmandsen. 1985. Radioglaciology. Dordrecht, etc., D. Reidel Publishing Co.

Dalziel, I.W.D. 1999. Tectonic setting of Lake Vostok. In Bell, R. E. and D. M. Karl, eds. Lake Vostok workshop final report, 7-8 November 1998, Washington D.C. New York, Columbia University Press, 17-19.

Glen, J. W. and J. G. Paren. 1975. The electrical properties of snow and ice. J. Glaciol., 15(73), 15-38.

Paterson, W. S. B. 1994. The physics of glaciers. Third edition. Oxford, etc., Elsevier.

Rasmussen, L.A. 1986. Refraction correction for radio echosounding of ice overlain by firn. J. Glaciol., 32(111), 192-194.

Rémy, F. and I. E. Tabacco. 2000. Bedrock features and ice flow near the EPICA ice core site (Dome C, Antarctica). Geophys. Res. Lett., 27(3), 405-409.

Rémy, F., P. Shaeffer and B. Legrésy. 1999. Ice flow physical processes derived from ERS-1 high-resolution map of Antarctica and Greenland ice sheet. Geophys. J. Int., 139(3), 645-656.

Retzlaff, R., N. Lord and C.R. Bentley. 1993. Airborne-radar studies: Ice Streams A, B and C, West Antarctica. J. Glaciol., 39(133), 495-506.

Tabacco, I. E., A. Passerini, F. Corbelli and M. Gorman. 1998. Correspondence. Determination of the surface and bed topography at Dome C, East Antarctica. J. Glaciol., 44(146), 185-191.

Tabacco, I. E., C. Bianchi, M. Chiappini, A. Passerini, A. Zirizzotti and E. Zuccheretti. 1999. Latest improvements for the echo sounding system of the Italian radar glaciological group and measurements in Antarctica. Ann. Geofis., 42(2), 271-276.

Twidale, C.R. 1997. The great age of some Australian landforms: examples of, and possible explanations for, landscape longevity. In Widdowson, M., ed. Palaeosurfaces: recognition, reconstruction and palaeoenvironmental interpretation. Vol. 120. London, Geological Society Publications, 13-23. 